\title{
Determinantes externos e internos da acumulação de capacidade tecnológica em empresas de bens de capital
}

por António Iacono e Marcelo Seido Nagano

RESUMO: Este artigo tem por objetivo analisar os principais elementos determinantes externos e internos às empresas para o acúmulo de capacidade tecnológica em empresas do setor de bens de capital no Brasil. Para alcançar tais objetivos, realizou-se um estudo exploratório, de abordagem qualitativa, junto a 44 empresas do setor de bens de capital mecânico, localizadas na região sudeste do país. O desdobramento em elementos internos e externos possibilitou a avaliação dos esforços internos realizados pelas empresas e as limitações postas pelos condicionantes externos que atuam no processo de acúmulo de capacidade tecnológica. Os resultados mostram que em todas as dimensões as características apresentadas condicionam as empresas a uma baixa competitividade, seja por preço ou por diferenciação tecnológica.

Palavras-chave: Capacidade Tecnológica; Bens de Capital; Inovação; Fatores Internos e Externos; Brasil

\section{Determinantes externos e internos de la acumulación de capacidades tecnológicas en las empresas de bienes de capital}

RESUMEN: Este artículo tiene como objetivo analizar los principales elementos externos e internos determinantes de la acumulación de capacidades tecnológicas en el sector de bienes de capital en empresas de Brasil. Para alcanzar tales objetivos se realizó un estudio exploratorio con enfoque cualitativo junto a 44 empresas del sector de bienes de capital mecánico, localizadas en la región sudeste del país. El desdoblamiento en elementos internos y externos posibilitó la evaluación de los esfuerzos internos realizados por las empresas y las limitaciones impuestas por los condicionantes externos que actúan en el proceso de acumulación de capacidades tecnológicas. Los resultados muestran que en todas las dimensiones las características presentadas condicionan a las empresas a una baja competitividad, ya sea por el precio o por diferenciación tecnológica.

Palabras clave: Capacidades Tecnológicas; Bienes de Capital; Innovación; Factores Internos y Externos; Brasil 


\section{The external and internal determining factors for the accumulation of technological capability in capital goods}

ABSTRACT: This study analyses the main external and internal determining factors for the accumulation of technological capability in capital goods companies in Brazil. These goals were achieved through an exploratory study with a qualitative approach conducted with 44 companies of the mechanical capital goods sector, located in the southeast region of the country. The internal and external factors were used to evaluate the internal efforts executed by the companies and the limitations posed by external constraints that influence the accumulation of technological capabilities. The results show that in all dimensions the characteristics presented induce companies to low competitiveness, either by price or technological differentiation.

Key words: Technological Capability; Capital Goods; Innovation; Internal and External Factors; Brazil

\section{António lacono}

toniacono@gmail.com

Doutorado em Engenharia de Produção, Universidade de São Paulo, Escola de Engenharia de São Carlos. Professor Adjunto, Universidade Federal Fluminense, Departamento de Engenharia de Produção, Volta Redonda-RJ, CEP 27255-125, Brasil.

Doctorado en Ingeniería y Producción Industrial, Universidad de São Paulo, Facultad de Ingeniería de São Carlos. Profesor Adjunto, Universidad Federal Fluminense, Departamento de Ingeniería de Producción, Volta Redonda-RJ, CEP 27255-125, Brasil.

$\mathrm{PhD}$ in Production Engineering, University of São Paulo, School of Engineering. Adjunct Professor, Fluminense Federal University, Production Engineering Department, Volta Redonda-RJ, CEP 27255-125, Brazil.
Marcelo Seido Nagano drnagano@usp.br

Doutorado em Engenharia Mecânica, Universidade São Paulo, Escola de Engenharia de São Carlos. Professor Associado, Universidade São Paulo, Departamento de Engenharia de Produção, Av. Trabalhador São-Carlense, 400, Centro, São Carlos-SP, CEP 13566-590, Brasil.

Doctorado en Ingeniería Mecánica, Universidad de São Paulo, Facultad de Ingeniería de São Carlos. Profesor Asociado, Universidad de São Paulo, Departamento de Ingeniería de Producción, Av. Trabalhador São-Carlense, 400, Centro, São Carlos-SP, CEP 13566-590, Brasil. $\mathrm{PhD}$ in Mechanical Engineering, University of São Paulo, School of Engineering of São Carlos. Associate Professor, University of São Paulo, Department of Production Engineering, Av. Trabalhador São-Carlense, 400, Centro, São Carlos-SP, CEP 13566-590, Brazil.

Recebido em março de 2016 e aceite em setembro de 2016. Recibido en marzo de 2016 y aceptado en septiembre de 2016. Received in March 2016 and accepted in September 2016. 
Nas últimas décadas houve uma intensificação da importância da inovação tecnológica para a competitividade das empresas e progresso econômico dos países. Cada vez mais, a competitividade em um mercado global depende da capacidade criativa e da capacidade tecnológica inovadora. É com base na capacidade tecnológica que as empresas realizam suas atividades de inovação e determinam seu grau de competitividade nos mercados atuantes.

A mudança tecnológica é entendida como um processo dinâmico e com uma natureza acumulativa. Tais características conduziram os estudos, em especial na abordagem evolucionista, à compreensão de regularidades setoriais nos determinantes da inovação. Conforme Malerba (2006), a inovação difere através dos setores e através das firmas em termos de diferentes conhecimentos, competências, diferentes níveis de processos de aprendizagem e organização das atividades inovativas, levando à configuração de também diferentes níveis de capacidade tecnológica. Com isso, a capacidade tecnológica assume importante papel como fonte de diferenças entre os setores industriais e países, em termos de progresso industrial e de crescimento econômico.

O acúmulo de capacidade tecnológica, por sua vez, compreende aspectos que são internos e externos às empresas. Do ponto de vista dos elementos internos, é crucial para a sobrevivência e competitividade, em um mercado globalizado, que as empresas se engajem em processos contínuos de aprendizagem para a construção e acúmulo de sua capacidade tecnológica, construção institucional e medidas políticas. Quanto aos elementos externos, além do mercado e da tecnologia, as flutuações do crescimento econômico exercem forte influência e interrupções no ciclo de aprendizagem, contribuindo assim para a ruptura da sequência evolutiva e cumulativa do processo de acúmulo de capacidade tecnológica. Em outros termos, os elementos externos criam condições desfavoráveis para investimentos, em particular, aqueles realizados com atividades com longo prazo de retorno, como as de Pesquisa \& Desenvolvimento (P\&D) e inovação.

As características ou fatores internos e externos à firma (ou inter e intrafirmas), apresentadas neste trabalho, apoiam-se nos conceitos de regime tecnológico e sistema setorial de inovação. O primeiro conceito, ao descrever o ambiente tecnológico no qual as firmas operam, gera um entendimento conseguinte das características ou fatores internos à firma. O segundo possibilita uma análise e entendimento de aspectos-chaves que vão além da própria firma (suas relações com os diversos agentes do meio externo), e que afetam consideravelmente suas atividades inovativas $\mathrm{e}$ produtivas.

Sendo assim, à luz da abordagem evolucionista, das concepções de regime tecnológico e de padrões e sistemas setoriais de inovação, este artigo tem por objetivo principal uma análise e sistematização das dimensões internas e externas que determinam o acúmulo de capacidades tecnológicas das
As características ou

fatores internos

e externos à firma (ou

inter e intrafirmas),

apresentadas neste

trabalho, apoiam-se nos

conceitos de regime

tecnológico e sistema

setorial de inovação.

O primeiro conceito, ao descrever o ambiente

tecnológico no qual

as firmas operam, gera

um entendimento

das características

ou fatores internos

à firma.

O segundo possibilita

uma análise

e entendimento

de aspectos-chaves que vão além da própria firma. 
empresas do setor de bens de capital no Brasil. Visa capturar evidências de esforços internos realizados pelas empresas e limitações para o acúmulo de capacidade tecnológica, postas pelos condicionantes externos.

Na seção a seguir é feita uma breve revisão sobre os principais conceitos em que se apoia este estudo. Logo após são apresentados os procedimentos metodológicos utilizados na pesquisa. Finalmente, os resultados e as considerações finais são mostrados na sequência.

\section{Regime tecnológico e sistema setorial de inovação}

O conceito de regime tecnológico foi introduzido por Nelson e Winter (1977) e elaborado por Dosi (1982), e define os princípios do conhecimento científico e tecnológico que são necessários para o processo de inovação, bem como as fronteiras que podem ser alcançadas. Literalmente, é um modelo ou padrão de solução para os problemas tecnológicos selecionados a partir de um processo de aprendizagem tecnológica, de resoluções que envolvem princípios científicos e procedimentos tecnológicos.

Em outros termos, o regime tecnológico pode ser definido em termos da combinação específica das condições de (i) oportunidade tecnológica (facilidade com a qual novas soluções tecnológicas podem surgir), (ii) condições de apropriabilidade (facilidade com a qual novas soluções podem ser protegidas contra as imitações), (iii) nível de cumulatividade do aprendizado (aprendizado obtido com inovações passadas influencia as inovações que ocorrerão no futuro), e (iv) natureza da base de conhecimento (propriedades do conhecimento no qual as atividades inovativas das firmas estão baseadas) (Dosi, 1988; Malerba e Orsenigo, 1993; Marsili e Verspagen, 2001). Sua estrutura teórica contribui para a compreensão da variedade de processos de inovação que é observada através dos setores industriais e da própria tecnologia.

Em outros termos, o regime tecnológico descreve o ambiente tecnológico no qual as firmas operam e enfatiza a importância dos padrões setoriais na mudança tecnológica. De acordo com Malerba (2002), um regime tecnológico específico define a natureza dos problemas que uma firma apresenta, em relação as suas atividades inovativas; afeta o tipo de aprendizagem tecnológica e, por conseguinte, a dinâmica da evolução dessas firmas. Vários outros estudos, em especial Malerba e Orsenigo (1996), Breschi, Malerba e Orsenigo (2000), e Van Dijk (2000) desenvolveram pesquisas empíricas sobre regimes tecnológicos a partir do modelo de Nelson e Winter.

Os fundamentos do conceito de Sistema Setorial de Inovação (SSI) estão nas diferenças entre os setores nas formas de aprendizado e de mudança técnica, associadas à definição de regime tecnológico. Um sistema setorial de inovação (e produção) é composto por um conjunto de agentes heterogêneos que desenvolvem interações de caráter mercadológico ou não mercadológico para a geração, adoção e uso de novas (ou já estabelecidas) tecnologias específicas e para a criação, produção e uso de novos produtos 
pertinentes a um setor (produtos setoriais). Os agentes que compõem um sistema setorial podem ser organizações (clientes, fornecedores, fabricantes, universidades, instituições financeiras, agentes governamentais, etc.) e indivíduos (Malerba, 2002).

Tal abordagem ganha muita importância, em especial, para os países em desenvolvimento, pois possibilita o entendimento de como as capacidades são desenvolvidas pelas empresas e setores no sentido de inovar e competir. O desenvolvimento de setores, a partir de escolhas acertadas, é fundamental para o desenvolvimento econômico do país. Nesse sentido, o SSI pode contribuir substancialmente para o desenvolvimento econômico, já que através desse modelo é possível identificar os elos faltantes, os gargalos na circulação do conhecimento e as causas de falhas no sistema. Deste modo, a especialização do SSI em alguns setores (mais dinâmicos tecnologicamente) pode ser um fator determinante para o dinamismo econômico.

A definição de SSI enfatiza, conforme Malerba (2002), alguns pontos que o distingue do conceito tradicional de setor, pois analisa outros agentes além das firmas.

Dentre os principais pontos de diferenciação, destacam-se:

- O sistema setorial privilegia o conhecimento e sua estrutura como elemento-chave. A base de conhecimento pode diferenciar-se muito através dos setores e afetar as atividades inovativas, organização e comportamento das firmas dentro de um setor;

- São enfatizados aspectos-chave da firma, tais como processo de aprendizagem, competências, comportamento e organização. A ênfase em identificar o grau e os determinantes da heterogeneidade dos agentes, comportamento e variedade organizacional dentro dos setores é uma característica da abordagem do sistema setorial;

- Importância do papel de organizações, tais como universidades, agentes financeiros, governo, e de regulações, padrões e mercado de trabalho. Estas características diferem fortemente entre os setores e afetam as atividades inovativas e produtivas das firmas;

- Mecanismos de interações internas e externas à firma. Relações entre os agentes, sejam elas de mercado ou não.

Essa potencialidade do SSI, conforme Lundvall et al. (2009), tem justificado, cada vez mais, a adoção desse modelo por países em desenvolvimento. Mas é importante enfatizar que, para que isso ocorra, é também necessária a criação de instituições adequadas, uma coordenação do sistema e a existência de uma infraestrutura capaz de apoiar e promover os processos.

\section{Acumulação de capacidade tecnológica em países em desenvolvimento}

Desde a década de 1970, a literatura sobre tecnologia e desenvolvimento tem enfatizadzo a aquisição de capacidade tecnológica, nos países em desenvolvimento, como um determinante crucial da industrialização bem-sucedida (Romijn, 1997). De uma maneira simples, a capacitação tecno-
O Sistema Setorial de Inovação pode contribuir substancialmente para o desenvolvimento econômico, já que através desse modelo é possível identificar os elos faltantes, os gargalos na circulação do conhecimento e as causas de falhas no sistema. Deste modo, a especialização em alguns setores (mais dinâmicos tecnologicamente) pode ser um fator determinante para o dinamismo econômico. 
lógica refere-se ao processo de acumulação de capacidades tecnológicas, por meio dos vários processos subjacentes de aprendizagem, conforme Figueiredo (2004).

Conforme Lall (1992; 2005), a capacidade tecnológica requer um esforço interno para o domínio, adaptação e aperfeiçoamento de novas tecnologias. A maquinaria está disponível igualmente para todos os países; no entanto, os elementos não incorporados da tecnologia não podem ser adquiridos ou transferidos como produtos físicos. O conhecimento tecnológico é difícil de se localizar, assim como sua transferência não pode ser incorporada nos equipamentos, instruções, patentes, projetos ou esquemas. Os conhecimentos incorporados só poderão ser usados da melhor maneira possível se forem complementados por diversos elementos tácitos que terão de ser desenvolvidos localmente.

Em outros termos, há a necessidade de desenvolvimento de um aprendizado local. A transferência necessariamente requer aprendizagem porque as tecnologias são de caráter tácito, e seus princípios subjacentes não são sempre claramente entendidos. Para os países em desenvolvimento, não é uma tarefa simples desenvolver habilidades, experiências e esforços que permitam que as empresas de um país adquiram, utilizem e adaptem, aperfeiçoem e criem tecnologias com eficiência.

Para Bell e Pavitt (1993; 1995), a capacidade tecnológica consiste nos recursos necessários para gerar e gerir as mudanças técnicas, e inclui, em especial, habilidades, conhecimentos, experiências e estrutura institucional. Tais recursos, uma vez acumulados, são incorporados às pessoas e aos sistemas organizacionais.

Nesse sentido, pode-se afirmar, conforme Figueiredo (2004; 2009), que a capacidade tecnológica de uma empresa (ou de um setor industrial) está armazenada e acumulada, em pelo menos quatro componentes, a saber:

- Sistemas técnicos físicos: Referem-se à maquinaria e equipamentos, sistemas baseados em tecnologia de informação, software em geral e plantas de manufatura;

- Pessoas (conhecimento e qualificação): referem-se ao conhecimento tácito, às experiências e habilidades de gerentes, engenheiros, técnicos e operadores que são adquiridos ao longo do tempo, mas que também abrangem sua qualificação formal;

- Sistema (tecido) organizacional: refere-se ao conhecimento acumulado nas rotinas organizacionais e gerenciais das empresas, nos procedimentos, nas instruções, na documentação, na implantação de técnicas de gestão (total quality management - TQM; material requeriment planning - MRP, just in time - JIT, etc.);

- Produtos e serviços: referem-se à parte mais visível da capacidade tecnológica e refletem o conhecimento tácito das pessoas e da organização e dos seus sistemas físicos e organizacionais. Por exemplo, nas atividades de desenho, desenvolvimento de prototipagem, teste, produção, e na parte de 
comercialização de produto e serviços, estão refletidos os outros três componentes da capacidade tecnológica.

A capacidade tecnológica será então a capacidade das empresas para criar, adaptar, gerir e gerar esses quatros componentes e a interação entre eles. Uma representação na Figura 1 mostra as quatro dimensões.

É importante ressaltar que entre as quatro dimensões existe um grau de importância e prioridade, em se tratando de economias em desenvolvimento. As empresas nesses países normalmente iniciam seus negócios a partir de tecnologias importadas de países de alto desenvolvimento industrial.

Conforme destacado por Lall (2000), uma vez que a tecnologia é importada, o seu uso eficiente requer a criação de novos conhecimentos e habilidades para dominar os seus elementos tácitos. Por essa razão, os componentes recursos humanos e sistemas organizacionais e gerenciais são mais exigidos e têm importância maior do que sistemas técnico físicos e produtos e serviços. Os sistemas técnico físicos (máquinas, equipamentos, software) podem ser facilmente adquiridos no mercado global, enquanto que os recursos humanos e o sistema organizacional (em função da especificidade das rotinas organizacionais) dificilmente são comercializáveis. Por essa razão, tais dimensões precisam ser desenvolvidas internamente, já que é a partir delas que as tecnologias adquiridas de outras empresas e países serão assimiladas, absorvidas, e posteriormente, alteradas, aprimoradas e até transformadas em novas tecnologias (Figueiredo, 2009).

As capacidades tecnológicas acumuladas podem ser subdivididas em capacidade de produção/operação e em capacidades tecnológicas inovadoras, conforme Bell e Pavitt (1993) (ver Figura 2). As primeiras incorporam recursos para a produção de bens industriais a determinados níveis de

Figura 1 Dimensões da capacidade tecnológica

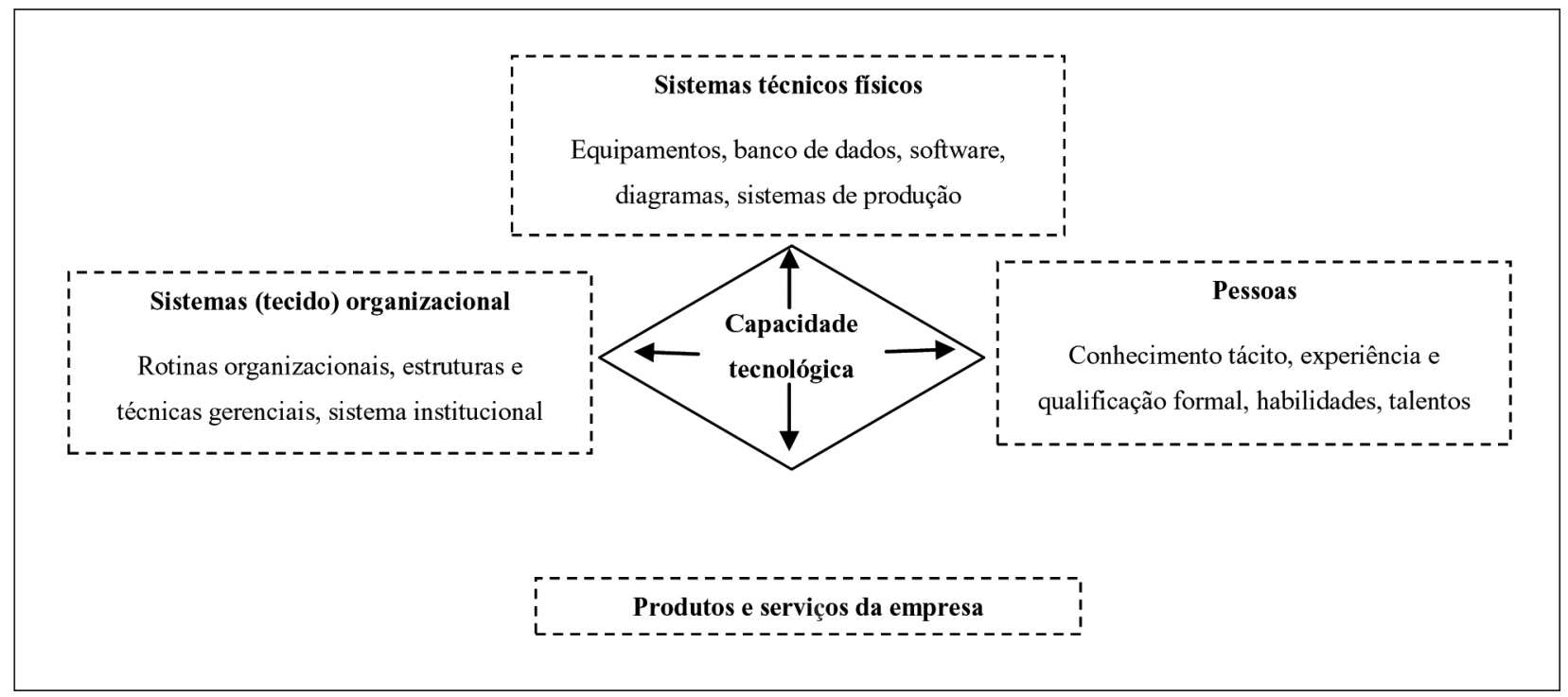

Fonte: Figueiredo (2004) 
eficiência, por meio de equipamentos (tecnologia incorporada), habilidades de operação no trabalho (operando e gerenciando know-how e experiência), métodos organizacionais, entre outros.

Segundo Figueiredo (2009), a distinção entre os tipos de capacidades (produção/operação e de inovação) é importante, em especial para empresas de países em desenvolvimento, pois uma empresa pode apresentar uma capacidade tecnológica avançada de produção e nenhuma ou limitada capacidade tecnológica para inovação. A acumulação de ambos os tipos de capacidade tecnológica poderá gerar um aperfeiçoamento de desempenho ambiental, operacional e financeiro, ou seja, liderança de mercado, aumento de produtividade, melhoria de qualidade de processos e produtos, redução de custos, etc. (ver Figura 3, p. 48).

\section{Estrutura do ambiente institucional}

Na opinião de Kim (2005), a estrutura do ambiente institucional é um elemento fundamental para a promoção dos processos de aprendizagem tecnológica. As experiências históricas de crescimento econômico sustentado têm encontrado dentro de um rico conjunto de instituições complementares, normas de comportamento compartilhadas e políticas

Figura 2 Acumulação tecnológica: conceitos e termos básicos

\section{A distinção entre os tipos de capacidades (produção/operação e de inovação) é importante, em especial para empresas de países em desenvolvimento, pois uma empresa pode apresentar uma capacidade tecnológica avançada de produção e nenhuma ou limitada capacidade tecnológica para inovação.}

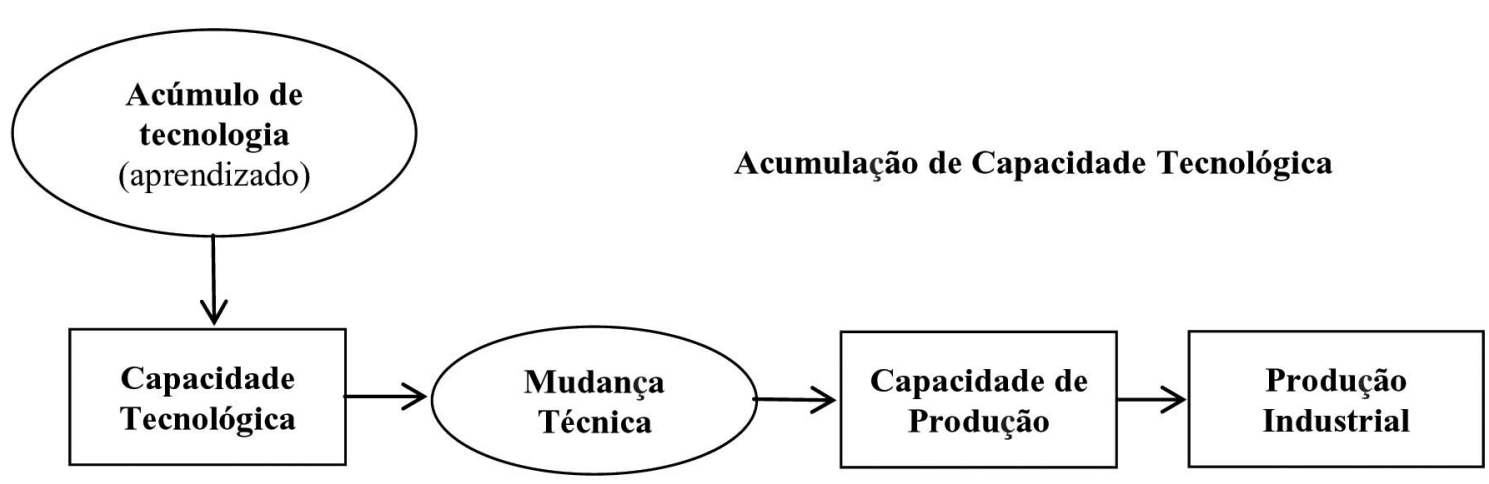

Recursos necessários para gerar e gerenciar a mudança técnica: (1) conhecimento, habilidades e experiência; (2) estruturas institucionais e conexões:

- dentro das empresas,

- entre empresas,

- entre empresas e outras instituições. (a) tecnologia incorporada em novos produtos e/ou novas plantas através de grandes investimentos (b) adaptação incremental e melhoria da capacidade de produção existente
Componentes dos sistemas de produção dados:

- capital fixo

- habilidades de operação no

trabalho e conhecimento

- especificações do produto/design

- especificações de entrada

- organização e procedimentos da produção
Produção

Industrial

Fonte: Bell e Pavitt (1993) 
públicas, as condições que as tornam possíveis. Conforme Cimoli et al. (2006), o ativo apoio governamental ao processo de catching-up, por meio de políticas públicas, tem sido considerado um importante ingrediente das estratégias de desenvolvimento nacional, especialmente em países naquele processo de convergência, com apoio e promoção do processo de aprendizado tecnológico. Os diferentes domínios de intervenção das políticas afetam as capacidades tecnológicas das organizações individuais e corporativas, e o ritmo em que elas conseguem aprender. As combinações apropriadas de políticas podem ajudar a promover novas trajetórias de desenvolvimento.

Para Kim (2005), as políticas públicas podem impactar significativamente no processo de aprendizado tecnológico, por meio de políticas industriais, de comércio e de ciência e tecnologia. As políticas públicas afetam as interações das empresas tanto com a comunidade internacional, ao regulamentar o afluxo de tecnologias estrangeiras, quanto com a comunidade nacional, na medida em que influenciam a disponibilidade e a eficácia das instituições de apoio nacionais e a qualidade das instituições educacionais. Em outros termos, essas políticas definem os ambientes macroeconômicos em que as empresas têm de operar, atingindo direta e indiretamente o processo de aprendizado tecnológico.

No entanto, outros fatores, além das políticas públicas, podem influenciar o processo de aprendizagem. Conforme Kim (2005), tais fatores compreendem o ambiente de mercado e de tecnologia, educação formal, ambiente sociocultural, e estrutura organizacional.

Figura 3 Capacidade tecnológica e seus impactos

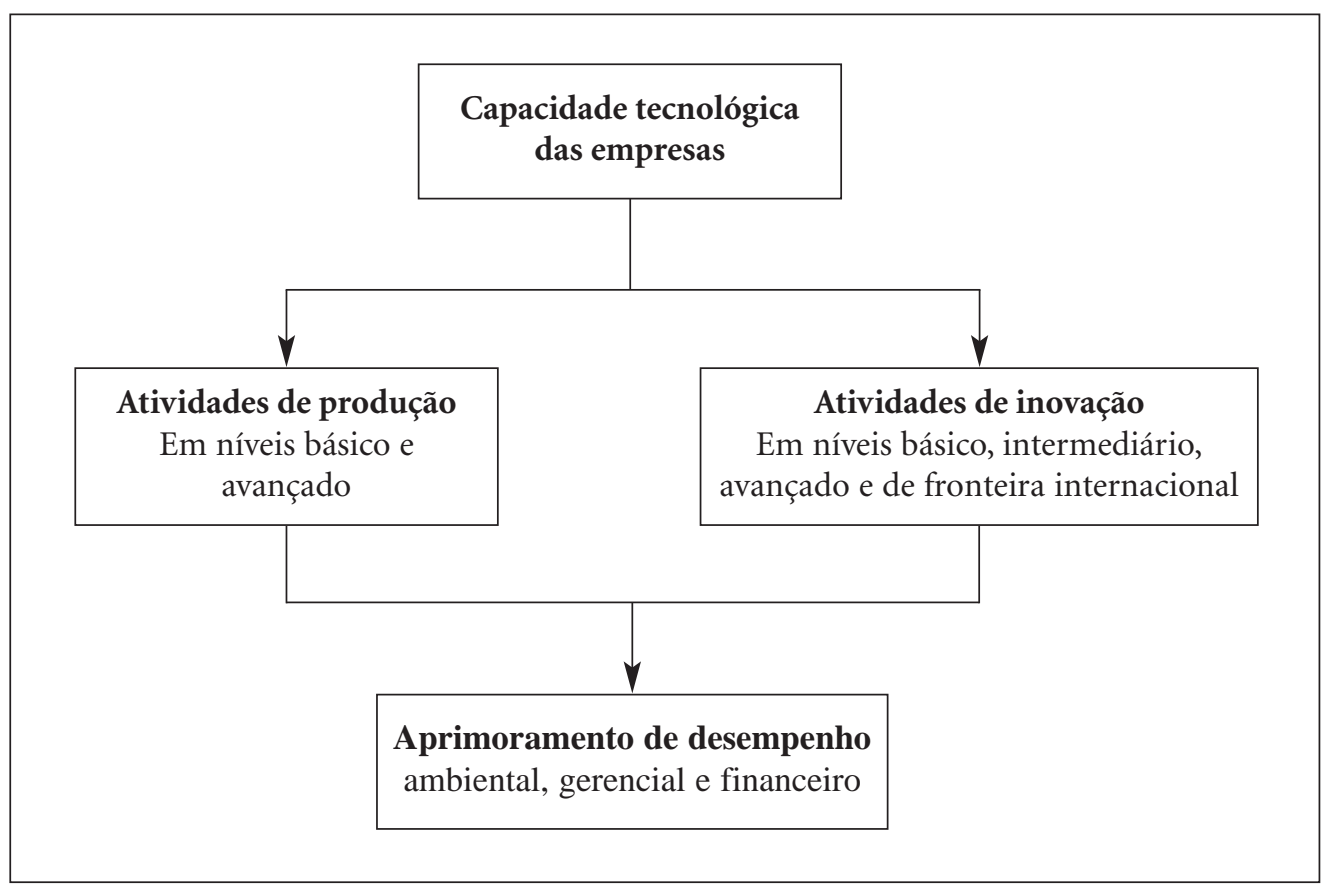

Fonte: Figueiredo (2009) 
O fator ambiente de mercado e de tecnologia influencia, além da própria empresa, o comportamento dos fornecedores, clientes e formuladores de políticas, e as interações que ocorrem entre eles. O processo de mudanças tecnológicas e as forças de mercado que atuam sobre esses elementos forçam as empresas a intensificarem seus esforços para fortalecerem as atividades internas, bem como para desenvolverem sua capacidade tecnológica. Levam as empresas a intensificarem também suas atividades externas para fortalecerem seus processos de aprendizado a partir de fontes externas.

A educação formal, em termos de estrutura e qualidade educacional, afeta a acumulação de capacidade tecnológica empresarial. Os recém-formados pelas instituições do sistema de educação formal proporcionam às empresas um contínuo ingresso de novos conhecimentos e de novas habilidades, que ampliam sua capacidade tecnológica para o futuro aprendizado.

O ambiente sociocultural, compreende as crenças, as normas e os valores da sociedade que impactam significativamente na formação ética do trabalho, a qual, por sua vez, influencia a mentalidade e o comportamento das pessoas nas empresas.

Por fim, a estrutura organizacional, refere-se a como as organizações são estruturadas e administradas. Tais características diferem entre as empresas e determinam, por sua vez, o nível de incentivos dentro da organização capaz de estimular a energia e as habilidades das pessoas. Um ambiente organizacional adequado favorece o aprendizado efetivo de seus membros e sua conversão em capacidade organizacional. Ambientes caracterizados por uma estrutura rígida criam barreiras para a criatividade das pessoas e retardam, por conseguinte, o aprendizado individual e organizacional.

\section{Procedimentos metodológicos}

Este estudo foi estruturado para analisar os principais elementos determinantes internos e externos para o acúmulo da capacidade tecnológica em empresas da indústria brasileira de bens de capital.

Quanto aos elementos internos, incluem-se a análise da capacitação em produção (habilidades associadas à operação); capacitação em recursos humanos (habilidades associadas ao acúmulo de conhecimentos obtidos pelos empregados); e capacitação em desenvolvimento (habilidades associadas à $\mathrm{P} \& \mathrm{D}$, projetos).

Do ponto de vista dos elementos externos, são de referir uma análise do setor no contexto brasileiro, abordando as implicações ou impacto de suas políticas industriais, arranjo institucional, mercado, e políticas macroeconômicas, em seus diferentes níveis de interação, sobre a capacitação e competitividade das empresas.

As dimensões e as variáveis utilizadas para o alcance dos objetivos propostos são apresentadas na Tabela 1 (ver p. 50). 
50| Revista de GESTÃO dos Países de Língua Portuguesa

Tabela 1 Dimensões e variáveis definidas para a pesquisa

\begin{tabular}{|c|c|c|c|}
\hline & Dimensões & Variáveis & Referências \\
\hline \multirow{20}{*}{ 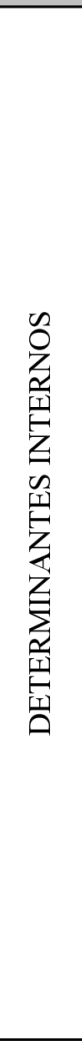 } & \multirow{4}{*}{ Recursos Internos } & Recursos financeiros & \multirow{4}{*}{$\begin{array}{l}\text { Dahlman et al. (1987); Figueiredo (2004); } \\
\text { Dahlman et al. (1987); Furtado (1994); } \\
\text { Bell e Pavitt (1995); Furtado (1994); } \\
\text { Hasenclever e Cassiolato (1998); Costa e } \\
\text { Cunha (2001); Varum e Monteiro (2007); } \\
\text { Radosevic (1999) }\end{array}$} \\
\hline & & Investimentos & \\
\hline & & Recursos humanos & \\
\hline & & Recursos físicos & \\
\hline & \multirow{3}{*}{ Engenharia de Processo/Produção } & Flexibilidade da Produção & \multirow{3}{*}{$\begin{array}{l}\text { Lall (1992); Figueiredo (2004); Bell e } \\
\text { Pavitt (1995); Amsden (2001); }\end{array}$} \\
\hline & & Confiabilidade da produção & \\
\hline & & Custo de produção & \\
\hline & \multirow{2}{*}{ Engenharia da Qualidade } & Gestão da qualidade & \multirow{2}{*}{$\begin{array}{l}\text { Lall (1987); Figueiredo (2004); Bell e } \\
\text { Pavitt (1995) }\end{array}$} \\
\hline & & Controle da qualidade & \\
\hline & \multirow{3}{*}{ Engenharia de Produto } & Atividades de P\&D & \multirow{3}{*}{$\begin{array}{l}\text { Breschi e Malerba (1997); Bell e Pavitt } \\
\text { (1995); Fransman (1986); Stewart (1977); } \\
\text { Cohen e Levinthal (1989) }\end{array}$} \\
\hline & & Engenharia reversa & \\
\hline & & Inovações & \\
\hline & \multirow{4}{*}{ Aprendizagem Tecnológica } & Aquisição externa de conhecimento & \multirow{4}{*}{$\begin{array}{l}\text { Kim (2005); Breschi e Malerba (1997; } \\
\text { 2002); Stewart (1977); Radosevic (1999); } \\
\text { Lee (1996); Tseng e Piller (2003); Van } \\
\text { Dijk (2000); Malerba e Orsenigo (2000) }\end{array}$} \\
\hline & & Aquisição interna de conhecimento & \\
\hline & & Socialização do conhecimento & \\
\hline & & Codificação do conhecimento & \\
\hline & \multirow{4}{*}{$\begin{array}{l}\text { Padrão de comportamento para a } \\
\text { inovação }\end{array}$} & Estratégia & \multirow{4}{*}{$\begin{array}{l}\text { Tidd e Bessant (2009); Burgelman, } \\
\text { Christensen e Wheelwright (2009); Teece } \\
\text { et al. (1990); Freeman (1997) }\end{array}$} \\
\hline & & Processos & \\
\hline & & Organização & \\
\hline & & Interação e ações conjuntas & \\
\hline \multirow{7}{*}{ 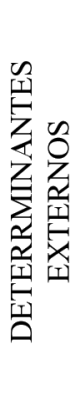 } & \multirow{5}{*}{ Ambiente macroeconômico } & Política cambial & \multirow{5}{*}{$\begin{array}{l}\text { Pich et al. (2002); Oreiro et al. (2009); } \\
\text { Lall (1987); Lundvall (2000;1992); } \\
\text { Bergek et al. (2008); Sahal (1984); } \\
\text { Rosenberg (1963); Tidd e Bessant (2009) }\end{array}$} \\
\hline & & Política comercial & \\
\hline & & Política tributária & \\
\hline & & Taxa de juros & \\
\hline & & Logística & \\
\hline & \multirow[t]{2}{*}{ Sistema setorial de bens de capital } & $\begin{array}{l}\text { Infraestrutura educacional } \\
\text { Fomento à inovação } \\
\end{array}$ & \multirow{2}{*}{$\begin{array}{l}\text { Lall (1987); Lundvall (2000;1992); } \\
\text { Bergek et al. (2008); Malerba (2002); } \\
\text { Pavitt (1984); Marsili e Verspagen (2001); } \\
\text { Cimoli et al. (2006); Peneder (2003) }\end{array}$} \\
\hline & & Política de Ciência e Tecnologia & \\
\hline
\end{tabular}

\section{Determinantes externos}

- Ambiente macroeconômico: Visa analisar e diferenciar em qual intensidade as condições externas às empresas estimulam ou não os processos de aprendizagem e as estratégias para acúmulo de capacitações. O comportamento dos fatores macroeconômicos, tais como política cambial, comercial e tributária podem inibir substancialmente os investimentos em recursos humanos e físicos para a capacitação.

- Sistema setorial de bens de capital: Visa identificar as características do ambiente tecnológico que definem as estratégias adotadas pelas empresas. Busca-se diferenciar as condições que determinam a demanda por novas tecnologias e os estímulos por investimentos em novos recursos e 
mecanismos de aprendizagem para atendê-las. Foca nos agentes heterogêneos que desenvolvem interações de caráter mercadológico ou não mercadológico para a geração, adoção e uso de novas (ou já estabelecidas) tecnologias específicas e para a criação, produção e uso de novos produtos pertinentes ao setor. Envolve a análise de clientes, fornecedores, fabricantes, universidades, instituições financeiras, agentes governamentais, entre outros.

\section{Determinantes internos}

- Recursos internos: Visa identificar o grau de disponibilidade e qualidade de recursos de pessoal e físicos que as empresas dispõem para os processos de acúmulo de capacidade tecnológica. São também avaliados os potenciais financeiro e de investimento das empresas.

- Engenharia de processo/produção: Analisa o desempenho das competências ou habilidades de produção das empresas. Visa diferenciar a capacidade tecnológica de produção e de inovação das empresas, ou seja, capacidade que as empresas possuem para o uso/operação de tecnologias e de sistemas de produção existentes, e capacidade para gerar novas soluções tecnológicas. A capacidade tecnológica para inovação passa pela capacidade tecnológica de produção.

- Engenharia da qualidade: Analisa o engajamento das empresas nas atividades voltadas para a área da qualidade. Visa diferenciar as empresas quanto à intensidade e práticas adotadas de gestão da qualidade.

- Engenharia de produto: Visa identificar e diferenciar os esforços tecnológicos das empresas para a inovação. Os esforços tecnológicos determinam se as atividades estão voltadas para a melhoria do conteúdo tecnológico, para o desenvolvimento ou aperfeiçoamento de novos produtos e processos. Analisa-se o esforço empreendedor contínuo, em termos de dispêndios para as atividades de pesquisa e desenvolvimento, e o grau de novidade atribuído ao produto, a partir dessas atividades.

- Aprendizagem tecnológica: Foca nos processos pelos quais a aprendizagem individual se converte em organizacional, já que a acumulação de saber tácito e de saber codificado, separadamente, não conduz à criação de uma base de conhecimentos na empresa. Visa determinar a intensidade em que os mecanismos de aprendizagem ocorrem ou estão presentes na organização, caracterizada como rara, intermitente (ou esporádica), e contínua.

- Padrão de comportamento para a inovação: Visa analisar o padrão de comportamento que promove a capacidade de inovar das empresas, bem como as habilidades para organizar e gerenciar o processo. Visa diferenciar as empresas quanto à importância da inovação como elemento estratégico; ao grau de organização de seus processos; ao grau de interação das empresas e de ações conjuntas nos processos de inovação; e ao ambiente para a inovação. 


\section{Composição da amostra}

A seleção da amostra teve como ponto de partida o setor de bens de capital mecânico - máquinas e equipamentos, subdividido em quatro subsetores, segundo a Classificação Nacional de Atividades Econômicas CNAE 2.0:

- CNAE 28.1 - Motores, bombas, compressores e equipamentos de transmissão;

- CNAE 28.2 - Máquinas e equipamentos de uso geral;

- CNAE 28.4 - Máquinas-ferramenta;

- CNAE 28.6 - Outras máquinas e equipamentos de uso específico. A escolha dos subsetores referidos acima se deve à sua representatividade na formação bruta de capital fixo (FBCF), que é de aproximadamente 70\%. Além das empresas pertencerem a um dos subsetores acima mencionados, outros critérios de seleção foram utilizados:

- Porte das empresas: o estudo optou por empresas de pequeno, médio e grande portes, segundo o critério de número de funcionários. Embora o critério por faturamento seja bastante utilizado, nem todas as empresas selecionadas para esta pesquisa puderam disponibilizar essa informação. A classificação das empresas, segundo o número de funcionários para o setor industrial, conforme Sebrae (2013): micro (até 19 funcionários); pequena (de 20 a 99 funcionários); média (de 100 a 499 funcionários); e grande (acima de 499 funcionários).

- Localização: a região escolhida foi a sudeste, por abranger a parcela mais representativa de empresas do setor.

- Origem das empresas: em função da natureza do estudo, que é o de analisar aspectos da capacidade tecnológica, internos e externos às empresas, foram selecionadas somente empresas fabricantes locais, ou seja, que possuem plantas industriais no Brasil.

\section{Perfil da amostra}

Para examinar os principais elementos determinantes internos e externos para o acúmulo da capacidade tecnológica, foram selecionadas 44 empresas do setor de bens de capital. Deste total, $90 \%$ estão presentes no mercado há mais de 20 anos, sendo $40 \%$ com presença há mais de 50 anos. Foram entrevistados informantes-chave em cada empresa, dentre os quais, gerentes e diretores das áreas técnica, comercial e industrial, das empresas.

As atividades principais realizadas pelas empresas pesquisadas compreendem a fabricação de máquinas e equipamentos, com $81 \%$ da amostra, e fabricação de componentes, com 19\%. O destino dos produtos fabricados abrange diversos setores e segmentos da economia, tais como papel e celulose, mineração, petróleo e gás, alimentos e siderúrgico.

As vendas estão concentradas no mercado interno, com um total de $79,5 \%$ das empresas que comercializam mais de $80 \%$ de seus produtos no país. A exportação não ocorre em $31,8 \%$ das empresas e somente $16 \%$
As vendas estão concentradas no mercado interno, com um total de $79,5 \%$ das empresas que comercializam mais de $80 \%$ de seus produtos no país. A exportação não ocorre em $31,8 \%$ das empresas e somente $16 \%$ exportam de $21 \%$ a $50 \%$ de sua produção. O volume de vendas para o mercado externo é considerado muito baixo. 
exportam de $21 \%$ a $50 \%$ de sua produção. O volume de vendas para o mercado externo é considerado muito baixo. Aproximadamente $84 \%$ das empresas exportam até $20 \%$ de seu volume de produção, sendo que deste total $56 \%$ não superam os $5 \%$.

\section{Resultados sobre determinantes internos da capacidade tecnológica}

Os casos que representam a amostra apontam para aspectos positivos, que apoiam e estimulam os processos de acúmulo de capacidade tecnológica, mas também para aspectos negativos, que servem de obstáculos ou inibidores. Uma síntese das principais características dos determinantes internos e externos da capacidade tecnológica é mostrada nas Tabelas 2A, 2B e $2 \mathrm{C}$.

A amostra apresenta uma importante heterogeneidade em relação às condições das empresas respondentes. Embora as empresas façam parte de um mesmo setor, os inúmeros e diversificados nichos de mercado nos quais atuam, bem como a complexidade e especificidade mostrada nos produtos, geram diferentes condições e necessidades. Mas há características que são comuns à maioria das empresas, independentemente das condições, dos produtos ou dos nichos de mercado em que atuam.

Observando a Tabela 2A (ver p. 54), no que se refere aos recursos humanos, o grau de qualificação da mão de obra se mostra suficiente para as atividades atuais de operação na produção, mas para as atividades de inovação, a qualificação atual não atende às exigências, que demandam maior conhecimento científico e tecnológico. Observa-se a presença de poucos engenheiros nas atividades de fabricação, planejamento e controle da produção (PCP), qualidade e desenvolvimento de produtos. Como resultado, essas características criam barreiras para o acúmulo de capacidade de inovação, que, conforme Dahlman et al. (1987), é necessária para gerar ou adaptar novas tecnologias, desenvolver novos produtos e serviços que atendam melhor as necessidades específicas.

No que tange aos recursos físicos, ainda segundo a mesma Tabela 2A, o grau de atualização internacional de máquinas e equipamentos é parcial. Há empresas que operam com máquinas convencionais não integradas a um sistema de automatização. Máquinas mais avançadas do ponto de vista tecnológico resultam em maior repetitividade, maior precisão e maior produtividade, que, por sua vez, geram produtos de maior qualidade e custos de fabricação menores, fatores fundamentais para a competitividade das empresas.

Em termos de recursos financeiros, as empresas não apresentam maiores dificuldades em disponibilizar capital de giro próprio para as operações diárias e de rotina. No entanto, para investir com recursos próprios em projetos de novos produtos, máquinas, qualificação de pessoal, entre outros, o nível de dificuldade apresentado pelas empresas é elevado. Em muitos casos, embora se tenha um incremento em investimento na área tecnológica, 
Tabela 2A Sistematização das características apresentadas pelos determinantes internos da capacidade tecnológica nas empresas pesquisadas

\begin{tabular}{|c|c|c|}
\hline \multicolumn{2}{|c|}{ Determinantes } & Características \\
\hline \multirow{4}{*}{ 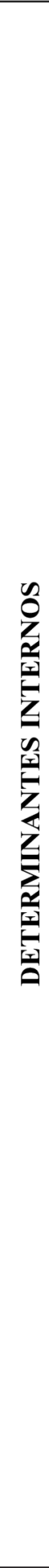 } & $\begin{array}{c}\text { Recursos } \\
\text { Financeiros/ } \\
\text { /Investimentos }\end{array}$ & $\begin{array}{l}\text { - } \quad \text { Capital de giro é um obstáculo representativo para as pequenas empresas } \\
\text { - } \quad \text { Recurvel elevado de dificuldade para investir com recursos próprios } \\
\text { - Investimentos insuficientes ou parcialmente insuficientes na área tecnológica } \\
\text { - Investimentos direcionados fundamentalmente para realização de melhorias } \\
\text { - Investimentos são dependentes da capacidade de oferta e de fatores } \\
\text { - } \text { Obtenção de financiamentos não é uma grande dificuldade para as empresas } \\
\text { - Dificuldade para obtenção de financiamentos é maior para empresas } \\
\text { - Bequenas e nacionais } \\
\text { - Baixa propensão ao risco } \\
\text { Baixa propensão ao investimento em projetos de novos produtos }\end{array}$ \\
\hline & $\begin{array}{c}\text { Recursos } \\
\text { Humanos } \\
\text { e } \\
\text { Físicos }\end{array}$ & $\begin{array}{l}\text { Humanos: capacitação para produção e desenvolvimento de produtos } \\
\text { - Grau de qualificação para as atividades operacionais na produção é } \\
\text { - Grau de qualificaçãa para as atividades de inovação é considerado } \\
\text { - } \quad \text { insuficiente } \\
\text { - Dificuldade de disponibilidade de mão de obra especializada no mercado } \\
\text { - Poucos engenheiros nas atividades de fabricação, PCP, qualidade e } \\
\text { desenvolvimento de produtos } \\
\text { Físicos: máquinas e equipamentos } \\
\text { - Grau de atualização de máquinas e equipamentos é parcial } \\
\text { - Presença de muitas máquinas convencionais, sem automatização } \\
\text { - Necessidade de substituição de máquinas ou equipamentos obsoletos } \\
\text { - Redução do custo operacional e aumento de capacidade produtiva são os } \\
\text { principais objetivos para a substituição }\end{array}$ \\
\hline & $\begin{array}{l}\text { Engenharia de } \\
\text { Produto }\end{array}$ & $\begin{array}{l}\text { - P\&D não estruturado } \\
\text { - } \quad \text { Predominância inovações para oçóes incrementais em empresas nacionais } \\
\text { - } \quad \text { Empresas transnacionais: inovações incrementais novas para o mercado } \\
\text { nacional, mas existentes no mercado mundial. } \\
\text { - } \quad \text { P\&D não é vista como obstáculo principal ao desenvolvimento da empresa } \\
\text { - Empresas transnacionais realizam predominantemente melhorias e } \\
\text { adaptações de produtos. O desenvolvimento de novos produtos é realizado } \\
\text { nas matrizes. } \\
\text { - } \quad \text { Paixa frequência de atividades de engenharia reversa } \\
\text { - }\end{array}$ \\
\hline & $\begin{array}{c}\text { Engenharia da } \\
\text { Qualidade }\end{array}$ & $\begin{array}{l}\text { - } \quad \text { Representa um obstáculo maior para o crescimento de empresas nacionais } \\
\text { - } \quad \text { Normas presença de técnicas de melhoria de desempenho da produção } \\
\text { nacionais } \\
\text { - } \quad \text { Desempenho da qualidade é mediano em empresas nacionais } \\
\text { - } \quad \text { Qualificação da mão de obra atende às necessidades para o nicho atual de } \\
\text { mercado } \\
\text { - Grau de qualificação de mão de obra insuficiente ou parcialmente } \\
\text { insuficiente para avançar em mercados com maior exigência tecnológica. } \\
\text { - Ausência de engenheiros especializados em qualidade } \\
\text { - Pouca atividade voltada para a melhoria contínua da qualidade dos produtos e } \\
\text { dos métodos de fabricação }\end{array}$ \\
\hline
\end{tabular}


os montantes são ainda considerados insuficientes ou parcialmente suficientes.

É importante destacar que as empresas, de maneira geral, não apresentam maiores dificuldades em obter financiamento para os projetos de inovação. Entretanto, verifica-se uma baixa propensão ao risco e ao investimento em novos produtos. Os projetos, fundamentalmente, são voltados para a realização de melhorias. A incerteza na capacidade de oferta e os riscos relacionados a fatores macroeconômicos inibem os investimentos, de maneira geral.

Quanto à engenharia de produto, observa-se que as empresas não apresentam uma estrutura organizada em P\&D. Considerando que o foco das empresas recai essencialmente na realização de melhorias, a falta de uma estrutura de P\&D não é vista, pelos respondentes, como um obstáculo importante para o crescimento das empresas. Em muitos casos, as atividades daquele tipo não são contínuas e não possuem pessoal dedicado exclusivamente ao desenvolvimento de novas soluções tecnológicas. Nota-se também uma baixa frequência em atividades contínuas de engenharia reversa.

A baixa frequência de atividades de $P \& D$ e a ausência de uma estrutura formal, verificada nas empresas, inibe a aquisição de novos conhecimentos tácitos, os quais são fundamentais para os processos de aprendizagem, que, por sua vez, conduzem ao acúmulo de capacidade tecnológica, conforme destacado em Figueiredo (2003).

Para os fabricantes nacionais, os principais incrementos tecnológicos incorporados nos produtos são novos para as empresas, mas já existentes no mercado nacional. As inovações para o mercado nacional são realizadas, em grande parte, pelas empresas transnacionais, e frequentemente desenvolvidas nas suas matrizes. Vale lembrar que as subsidiárias estrangeiras realizam no Brasil predominantemente melhorias e adaptações de produtos. Em outros termos, a baixa intensidade de esforços em atividades de P\&D nas empresas instaladas no Brasil retarda o acúmulo de capacidade tecnológica. Esse retardamento aumenta a diferença tecnológica (ou gap tecnológico) em relação às empresas inovadoras, já que a trajetória de acumulação de capacidade tecnológica, em fabricantes nacionais, se inicia quando as empresas inovadoras já acumularam estoque substancial de capacidade tecnológica.

Finalmente, na Tabela 2A, a engenharia da qualidade, em seu desempenho, pode ser avaliada a partir da exigência tecnológica dos nichos de mercado em que as empresas atuam. Vale lembrar que a qualidade, como habilidade técnica, é um processo de mudança técnica incremental, e que, para a maioria das empresas da amostra, é uma componente-chave para a estratégia de concorrência baseada na diferenciação. De acordo com Toledo (1990), considerando que o mercado competitivo das empresas baseia-se fundamentalmente na heterogeneidade de produtos, a diferenciação torna-se
As empresas, de maneira geral, não apresentam maiores dificuldades em obter financiamento para os projetos de inovação. Entretanto, verifica-se uma baixa propensão ao risco e ao investimento em novos produtos. Os projetos, fundamentalmente, são voltados para a realização de melhorias. 
um elemento crucial para a competitividade, pois pode complementar ou substituir a concorrência por preços.

De maneira geral, o desempenho da qualidade é considerado bom para as empresas transnacionais e mediano para as empresas nacionais. No entanto, ao tomar em conta nichos de mercado mais exigentes, os processos de produção e a qualificação da mão de obra são percebidos como insuficientes ou parcialmente suficientes. Verifica-se uma baixa presença de técnicas de melhoria de desempenho da produção e de normas de gestão e garantia da qualidade, pouca atividade voltada para a melhoria contínua em produtos e processos, e ausência, em grande parte das empresas, de engenheiros especializados na área, especialmente em empresas nacionais.

Vale destacar que há empresas em que a necessidade de melhoria da qualidade está mais voltada para os aspectos do produto, e requerem melhorias quanto à conformidade às especificações técnicas. Entretanto, para outras empresas, o foco da qualidade é direcionado para os processos, no qual se busca uma melhoria em sua capacidade com a redução de sua variabilidade permitida.

Quanto à engenharia de processo/produção, que se pode observar na Tabela 2B (ver p. 57), verifica-se um conjunto de aspectos positivos relacionados à flexibilidade e à confiabilidade da produção. De maneira geral, as empresas possuem habilidades importantes para a produção de produtos especiais e para ajustar a capacidade produtiva às flutuações da demanda. Outro aspecto positivo é a flexibilidade que o sistema de desenvolvimento de produto das empresas apresenta em criar pequenos projetos paralelos aos que se encontram já em andamento. Por outro lado, as empresas possuem baixa eficiência em custo, ou seja, quando apresentam dificuldades em produzir pequenas quantidades rentáveis.

No que se refere à confiabilidade, de maneira geral, o desempenho é considerado satisfatório, com destaque para lead time de produção reduzido e as entregas no tempo prometido. Vale destacar que a eficiência na entrega e no tempo de produção deve-se ao elevado grau de verticalização da produção apresentado por uma parcela de empresas. Por outro lado, para outra parcela de empresas, o desempenho nesses fatores é baixo e está diretamente relacionado à ausência de fornecedores especializados.

Quanto aos custos de produção, as empresas apresentam baixa eficiência operacional. Contribui para tal, a ausência de adoção de práticas ou técnicas voltadas para a redução do custo operacional.

Em relação à aprendizagem tecnológica, ainda segundo a Tabela $2 \mathrm{~B}$ observa-se, para diversos mecanismos de aprendizagem externa, interna e de socialização do conhecimento, uma baixa intensidade nas atividades relacionadas. As práticas contínuas com maior frequência são aquelas relacionadas à codificação do conhecimento. Os processos de aprendizagem ocorrem nas empresas, de maneira geral, esporadicamente, e tal intensidade não é suficiente para levar as empresas a uma efetiva aquisição de conhecimento e 
57|Revista de GESTÃO dos Países de Língua Portuguesa

Tabela 2B Sistematização das características apresentadas pelos determinantes internos da capacidade tecnológica nas empresas pesquisadas (continuação)

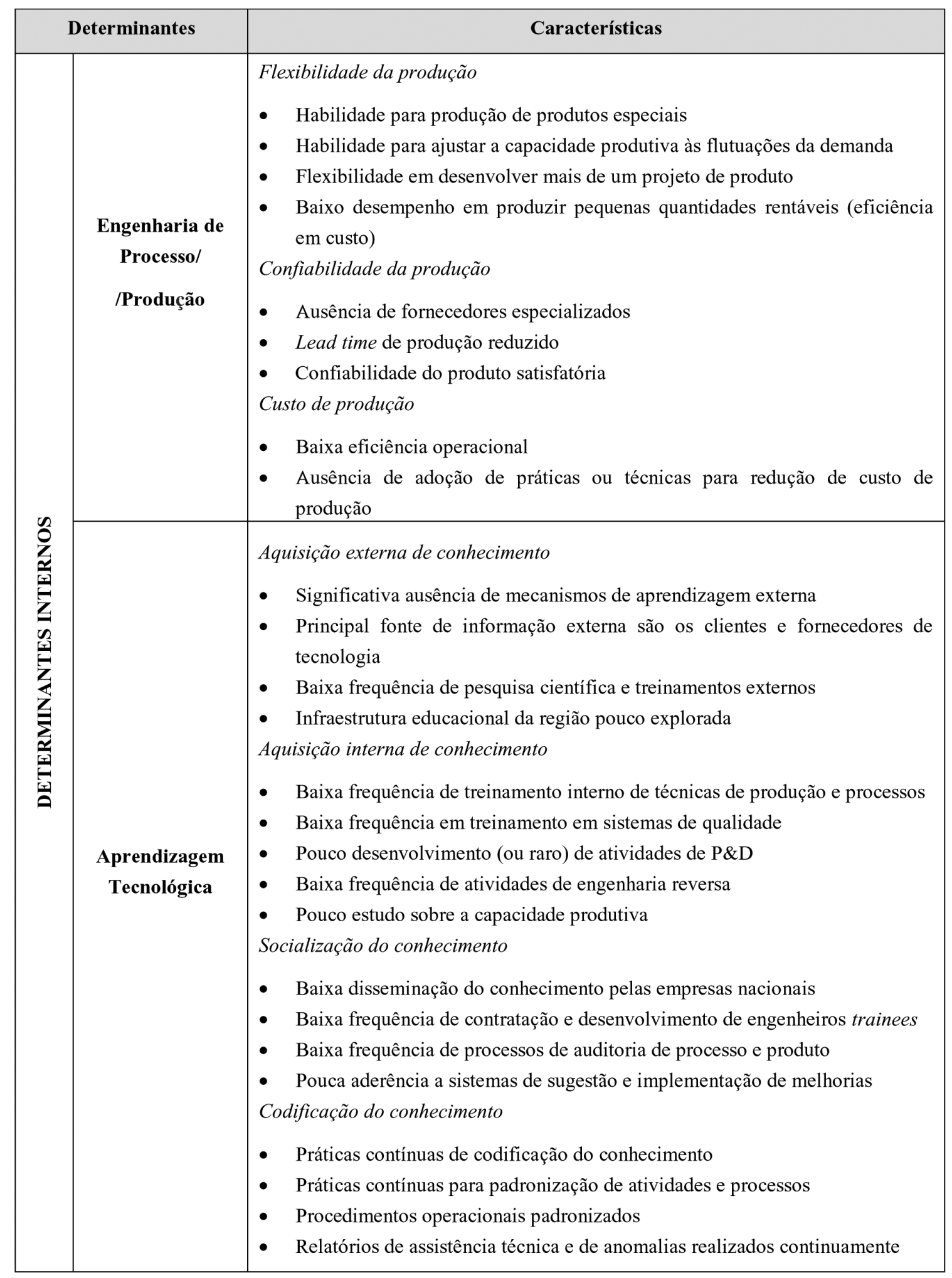


58|Revista de GESTÃO dos Países de Língua Portuguesa

nem à sua incorporação no plano organizacional. As atividades, quando contínuas, possibilitam a criação, a atualização e o aperfeiçoamento dos processos de aprendizagem ao longo do tempo, garantem um fluxo constante de saber externo da empresa, fazem com que se compreenda melhor a tecnologia adquirida e os princípios inerentes aos processos de aquisição de conhecimentos internos, e asseguram a constante conversão de aprendizagem individual em aprendizagem organizacional.

Dado o caráter complexo e sistêmico dos processos de aprendizagem, o uso de apenas um ou outro mecanismo, por mais eficiente que seja, como a interação com clientes e fornecedores ou o treinamento interno de técnicas de produção e processo, não é suficiente para promover a aprendizagem organizacional. É necessário aprimorar continuamente uma variedade de mecanismos em todos os níveis da empresa, para rotinizar a conversão de aprendizagem individual em aprendizagem organizacional.

Para países, caracterizados por uma industrialização tardia, como o Brasil, os processos de aquisição de saber externo e interno são cruciais para as empresas, já que elas não podem valer-se de uma base de conhecimento previamente adquirida. Tanto os processos de aquisição quanto de conversão são fundamentais para a acumulação de sua competência tecnológica (Figueiredo, 2003).

Segundo a Tabela 2C (ver p. 59), no que se refere ao padrão de comportamento para a inovação, observa-se uma determinada heterogeneidade nas dimensões analisadas. Um aspecto importante a ser destacado é o reconhecimento da inovação como elemento estratégico e a visão compartilhada dos principais executivos sobre o desenvolvimento da empresa pela inovação. Por outro lado, nota-se uma ausência ou uso muito limitado de ferramentas de prospecção tecnológica, fundamentais para a formulação e desdobramento das estratégias de inovação.

Quanto aos processos, verificam-se importantes potencialidades, como a flexibilidade e organização apropriada nos processos de desenvolvimento de produtos. Por outro lado, apesar de existir uma interação contínua com clientes, as empresas carecem de mecanismos eficazes para compreender suas necessidades. Os processos de desenvolvimento de produtos, embora sejam organizados, concentram-se, de maneira geral, no próprio departamento, ou seja, não há um envolvimento prévio maior de outros departamentos no desenvolvimento de produto. As organizações, em sua maioria, são flexíveis e possuem uma estrutura adequada para tomar rapidamente decisões. O ambiente de trabalho em equipe além dos limites departamentais é considerado outro aspecto positivo, mas a eficiência na comunicação e nas atividades através da organização apresenta limitações.

As características menos favoráveis, no que diz respeito ao comportamento inovador, são verificadas nas interações e ações conjuntas. Observa-se que as empresas pouco interagem com outras empresas e/ou instituições. A relação com as universidades são limitadas e divergentes, em muitos

\section{Para países,} caracterizados por uma industrialização tardia, como o Brasil, os processos de aquisição de saber externo e interno são cruciais para as empresas, já que elas não podem valer-se de uma base de conhecimento previamente adquirida. Tanto os processos de aquisição quanto de conversão são fundamentais para a acumulação de sua competência tecnológica. 
59|Revista de GESTÃO dos Países de Língua Portuguesa

Tabela 2C Sistematização das características apresentadas pelos determinantes internos da capacidade tecnológica nas empresas pesquisadas (continuação)

\begin{tabular}{|c|c|c|}
\hline & Determinantes & Características \\
\hline 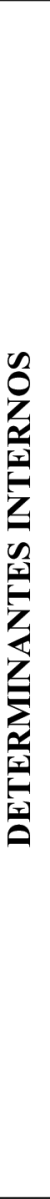 & $\begin{array}{c}\text { Padrão de } \\
\text { comportamento para a } \\
\text { inovação }\end{array}$ & $\begin{array}{l}\text { Estratégia } \\
\text { - } \quad \text { Reconhecimento da inovação como elemento estratégico } \\
\text { - } \quad \text { Ausência ou uso limitado de ferramentas de prospecção } \\
\text { tecnológica } \\
\text { - Visão compartilhada dos principais executivos sobre o } \\
\text { desenvolvimento da empresa pela inovação } \\
\text { Processos } \\
\text { - } \quad \text { Flexibilidade no desenvolvimento de produto } \\
\text { - } \quad \text { Processo de Desenvolvimento do Produto (DP) organizado e } \\
\text { apropriado } \\
\text { - } \quad \text { Ausência de mecanismos eficazes para compreender as } \\
\text { necessidades dos clientes } \\
\text { Pouco envolvimento prévio de todos os departamentos no } \\
\text { Organização } \\
\text { - Bom ambiente para trabalho em equipe além dos limites } \\
\text { - } \quad \text { departamentais } \\
\text { Interação e ações conjuntas } \\
\text { - Ausência ou baixa interação com universidades } \\
\text { - } \quad \text { Divergências com universidades em relação à propriedade } \\
\text { - } \text { Forte presença de barreiras culturais para ações conjuntas } \\
\text { - } \quad \text { Dificuldade presença de barreiras jurídicas para ações conjuntas } \\
\text { especializado }\end{array}$ \\
\hline
\end{tabular}

casos. Há barreiras culturais e jurídicas que inibem a troca de experiências e de conhecimento entre os atores.

As interações e o desenvolvimento de ações conjuntas são cruciais para a aquisição de conhecimento externo. Conforme já destacado, o desenvolvimento de ações conjuntas leva a aquisições de conhecimentos tácitos e codificados, fundamentais para a criação e acúmulo de competência tecnológica.

\section{Resultados dos determinantes externos da capacidade tecnológica}

No que tange aos elementos externos, tanto os fatores macroeconômicos quanto os relacionados ao sistema setorial representam importantes barreiras ao processo de acumulação de capacidade tecnológica e ao crescimento das empresas, conforme se verifica na Tabela 3. Como já se referiu, o acúmulo de capacidade tecnológica não está atrelado apenas aos processos intraorganizacionais, há condições externas à empresa que estimulam ou 
60|Revista de GESTÃO dos Países de Língua Portuguesa

não os processos de aprendizagem e as estratégias para acúmulo de capacitações.

O comportamento dos fatores macroeconômicos inibe substancialmente os investimentos em recursos humanos e físicos para a capacitação. A elevada taxa de juros gera um custo alto para financiamento de equipamentos, bem como os encargos e impostos praticados criam barreiras para a contratação de mão de obra mais qualificada. Tais elementos são cruciais para a aquisição de novos conhecimentos e fortalecimento de outros processos de aprendizagem.

O comportamento da taxa de câmbio representa para muitas empresas um risco econômico importante e restringe fortemente as políticas das empresas voltadas para a capacitação tecnológica e inovação, reduzindo os gastos nessa área.

O sistema setorial de inovação apresenta deficiências, em especial no que se refere a interação das empresas com a infraestrutura educacional. Há poucas instituições direcionadas ao setor de bens de capital. As interações se limitam a troca de informações, com baixa intensidade de ações conjuntas. $\mathrm{Na}$ concorrência pela inovação de produtos, conforme destacado por Ferraz et al. (1997), as relações com a infraestrutura científica e tecnológica constituem recurso fundamental para a competitividade da empresa.

Tabela 3 Sistematização das características apresentadas pelos determinantes externos da capacidade tecnológica nas empresas pesquisadas

\begin{tabular}{|c|c|c|}
\hline 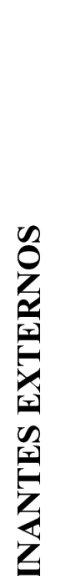 & Fatores macroeconômicos & $\begin{array}{l}\text { - Inibem investimentos em capacitação tecnológica } \\
\text { - Mitigam atividades externas para fortalecimento dos } \\
\text { processos de aprendizado a partir de fontes externas } \\
\text { - Influencia fortemente o desempenho das empresas no } \\
\text { mercado interno e externo } \\
\text { - Política cambial: inviabiliza ou dificulta a exportação } \\
\text { - Carga tributária: eleva fortemente de custo de produção e } \\
\text { dificulta a competitividade interna } \\
\text { - Carga tributária: dificulta a contratação de mão de obra } \\
\text { melhor qualificada } \\
\text { Custo logístico: pouco representativo para o mercado } \\
\text { interno } \\
\text { Custo logístico: muito representativo para o mercado } \\
\text { externo }\end{array}$ \\
\hline 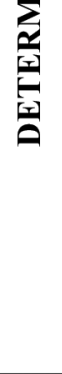 & $\begin{array}{c}\text { Sistema setorial de bens } \\
\text { de capital }\end{array}$ & $\begin{array}{l}\text { - Poucas instituições educacionais voltadas para o setor de } \\
\text { BK (business knowledge) } \\
\text { - } \quad \text { Baixa eficácia das instituições educacionais } \\
\text { - Programas de fomento com baixa aderência às necessidades } \\
\text { - } \quad \text { Fas empresas de informação e conhecimento sobre os programas } \\
\text { - } \quad \text { Disponibilidade de crédito e financiamento } \\
\text { - Tempo de resposta longo dos fomentos } \\
\text { - Pouca credibilidade nos órgão de fomento }\end{array}$ \\
\hline
\end{tabular}

Fonte: Elaborado a partir da pesquisa de campo 
61|Revista de GESTÃo dos Países de Língua Portuguesa

Há questões culturais e jurídicas, conforme já exposto, que de certa forma inibem o fortalecimento das relações. A limitação de ações conjuntas afeta o processo de aprendizagem e posterior atualização tecnológica.

Os programas de fomento apresentam baixa adesão às necessidades das empresas. As condições de financiamento excluem muitas empresas, seja pelo tempo de resposta longo para aprovação e liberação dos recursos, seja pelo montante disponibilizado.

\section{Considerações finais}

Este artigo teve como propósito principal investigar os principais elementos internos e externos à empresa, que são determinantes para o acúmulo de capacidade tecnológica em empresas do setor de bens de capital no Brasil. O desdobramento em elementos internos e externos possibilitou a avaliação dos esforços internos realizados pelas empresas e as limitações de acúmulo de capacidade tecnológica postas pelos condicionantes externos. A exploração desses elementos internos e externos implicou a construção de uma sistematização das principais dimensões que compõem a capacidade tecnológica apresentada pelas empresas.

A análise dos determinantes mostrou que em todas as dimensões as características apresentadas condicionam as empresas a uma baixa competitividade, seja por preço ou tecnologia. Do ponto de vista dos elementos internos, é crucial para a sobrevivência e competitividade, em um mercado globalizado, que as empresas se engajem em processos contínuos de aprendizagem para a construção e acúmulo de sua capacidade tecnológica.

Por outro lado, do ponto de vista dos elementos externos, as interrupções do ciclo de aprendizagem, determinadas pelas flutuações do crescimento econômico, contribuem para a ruptura da sequência evolutiva e cumulativa do processo de acúmulo de capacidade tecnológica. Em outros termos, a análise sugere que os elementos externos exercem forte influência no referido processo por criarem condições desfavoráveis para investimentos, em particular, aqueles realizados com atividades com longo prazo de retorno, como as de $\mathrm{P} \& \mathrm{D}$ e inovação.

Quanto à heterogeneidade, pode-se afirmar que está presente nas empresas, nos setores atendidos por elas e nos níveis tecnológicos dos produtos. Há condições e especificidades quanto ao porte e origem das empresas. As empresas nacionais e de pequeno porte apresentam, de maneira geral, maiores dificuldades para o acúmulo de capacidade tecnológica, pois são mais sensíveis às mudanças no ambiente. As empresas transnacionais e as nacionais de médio e grande portes, em grande parcela, apresentam um número maior de práticas contínuas que favorecem os processos de aprendizagem e o acúmulo de capacitações tecnológicas. Em especial, as empresas nacionais encontram maior dificuldade na exportação, pois o efeito dos fatores macroeconômicos sobre elas é maior.

A indústria de bens de capital apresenta características que concorrem

\author{
O sistema setorial \\ de inovação apresenta \\ deficiências, em especial \\ no que se refere \\ a interação das empresas \\ com a infraestrutura \\ educacional. Há poucas \\ instituições direcionadas \\ ao setor de bens \\ de capital. As interações \\ se limitam a troca \\ de informações, com \\ baixa intensidade \\ de ações conjuntas.
}


$62 \mid$ Revista de GESTÃO dos Países de Língua Portuguesa

para inibir a realização de atividades tecnológicas. Conforme exposto, há uma carência de especialização da produção, uma falta de escala, elevados custos unitários, baixa utilização de automação dos processos, e uma estrutura empresarial limitada. Tais características inviabilizam a competitividade das empresas, seja no mercado interno e externo.

Por outro lado, as empresas pesquisadas, embora encontrem alguma dificuldade em produzir e comercializar, de maneira geral, demonstram boa capacidade de fabricação, adaptação e realização de aperfeiçoamentos marginais. Entretanto, quando do projeto de produtos mais sofisticados, dependem da importação de tecnologia.

Em relação às políticas públicas, a atual política industrial e tecnológica brasileira dispõe de um conjunto de modalidades e programas. Há fomento à inovação direcionado em diversos sentidos: para a pesquisa científica e tecnológica; para a formação de recursos humanos; para a inovação na produção; para fortalecimento da engenharia; para inserção no comércio internacional; para incentivo à inovação; para modernização de máquinas e equipamentos, entre outros. Pode-se afirmar que, em princípio, os instrumentos de política pública cobrem muitas das necessidades apresentadas pelas empresas nas dimensões internas e externas para o acúmulo da capacidade tecnológica. Entretanto, é importante ressaltar que, apesar do aumento do número de empresas beneficiadas pelos programas e pela sua amplitude, a adesão é considerada baixa.

Esta fraca adesão está relacionada a vários fatores. As políticas públicas para a promoção de empresas inovadoras, de maneira geral, são homogeneizadas e diante de um setor muito heterogêneo e de especificidades organizacionais, conforme visto, torna-se necessário uma maior especialização tanto das agências de fomento quanto dos programas. A ausência de um tratamento especializado para o setor de bens de capital dificulta o acesso aos programas e submete os projetos de inovação das empresas do setor a outras divisões setoriais.

Por outro lado, quanto às empresas, é importante destacar a falta de informação sobre os programas e o pouco conhecimento em relação às questões da inovação. Conforme visto, as empresas apresentam uma baixa capacitação para o aprendizado tecnológico. Tal contexto, tem gerado pouca adesão aos estímulos lançados pela política de inovação.

Seja pela falta de informação, pelo modelo de inserção ou pelo pouco conhecimento das empresas sobre as questões da inovação, as políticas públicas voltadas para promover a capacitação tecnológica e inovação nas empresas têm apresentado resultados aquém do necessário e desejado. As empresas nacionais são as que apresentam maior necessidade. A viabilidade em projetos voltados para incorporação de tecnologias avançadas requer fortemente o apoio do Estado. Vale lembrar que os projetos de inovação apresentam elevados custos e riscos mercadológicos, e as empresas nacionais, em especial as de pequena e média dimensão, não dispõem de recursos próprios suficientes.

\section{A análise sugere \\ que os elementos externos exercem forte influência no referido processo por criarem condições desfavoráveis para investimentos, em particular, aqueles realizados com atividades com longo prazo de retorno, como as de P\&D e inovação.}


63|Revista de GESTÃo dos Países de Língua Portuguesa

Considerando a importância do preço e da tecnologia embutida nos equipamentos como fatores de competitividade, é crucial para as empresas o aumento da capacidade tecnológica e a adoção de práticas que conduzam à redução de custo. Políticas públicas que fortaleçam o apoio à tecnologia de produto, no sentido de estimular a engenharia de produto, por meio de financiamento subsidiado, são fundamentais para o acúmulo da capacidade tecnológica das empresas. Além do acúmulo de capacidade tecnológica, há necessidade de uma maior modernização dos equipamentos das empresas, de maior capacitação comercial, em especial no que se refere ao serviço pós-venda, de maior capacitação produtiva, com ênfase na qualidade, e de internacionalização das empresas nacionais.

Quanto às limitações desta pesquisa, a principal atenção deve-se à dificuldade de generalização. Tal dificuldade não está relacionada apenas ao tamanho da amostra, mas também à heterogeneidade apresentada pelo setor. A amostra caracterizou-se pelas diferenças apresentadas quanto aos produtos, aos mercados de atuação, ao porte e a origem das empresas. Há indicativos de comportamentos diferentes entre empresas nacionais e transnacionais, mas, por outro lado, há fatores que apresentam comportamentos comuns às empresas. Nesse sentido, uma ampliação no número de respondentes seria importante para a confirmação das similaridades e diferenças.

Para estudos futuros, um aspecto importante a ser considerado diz respeito às relações entre as variáveis. As análises realizadas das dimensões internas e externas sobre o acúmulo das capacidades tecnológicas sugerem relações entre variáveis, e, nesse sentido, um estudo com uma amostragem significativa e com uso de ferramentas de análise multivariada, forneceria um entendimento melhor dos determinantes e de suas inter-relações.

\section{Referências bibliográficas}

AMSDEN, A.H. (2001), The Rise of the Rest: Challenges to the West from Late-Industrializing Economie. Oxford University Press, Oxford.

BELL, M. e PAVITT, K. (1995), «The development of technological capabilities: Technology and international competitiveness». The World Bank, Washington.

BELL, M. e PAVITT, K. (1993), «Technological accumulation and industrial growth: Contrasts between developed and developing countries». Industrial and Corporate Change, v. 2, no. 1, pp. 157-210.

BERGEK A.; JACOBSSON, S.; CARLSSON, B.; LINDMARK, S. e RICKNE, A. (2008), «Analyzing the functional dynamics of technological innovation systems: A scheme of analysis». Research Policy, 37(3), pp. 407-429.

BRESCHI, S.; MALERBA, F. e ORSENIGO, L. (2000), «Technological regimes and Schumpeterian patterns of innovation». Economic Journal, v. 110, pp. 388-410.

BRESCHI, S. e MALERBA, F. (1997), «Sectorial system of innovation: Technological regimes, Schumpeterian dynamics and spatial boundaries». In C. Edquist (Ed.), System of Innovation. Francis Pinter, London.

BURGELMAN. R.A.; CHRISTENSEN, C.M. e WHEELWRIGHT, S.C. (2009), Strategic Management of Technology and Innovation. McGraw-Hill Irwin, Boston.

CIMOLI, M.; DOSI, G.; NELSON, R.R. e STIGLITZ, J. (2006), «Institutions and policies shaping industrial development: An introductory note». LEM Working Paper Series.

\section{Políticas públicas} que fortaleçam o apoio à tecnologia de produto, no sentido de estimular a engenharia de produto, por meio de financiamento subsidiado, são fundamentais para o acúmulo da capacidade tecnológica das empresas. 
$64 \mid$ Revista de GESTÃO dos Países de Língua Portuguesa

COHEN, W.M. e LEVINTHAL, D.A. (1989), Innovation and learning: The two faces of R\&D. The Economic Journal, no. 99, pp. 569-596.

COSTA, V.M.G. e CUNHA, J.C.A (2001), «Universidade e a capacitação tecnológica das empresas». Revista de Administração Contemporânea, 5(1), pp. 61-81.

DAHLMAN, C.; ROSS-LARSON, B. e WESTPHAL, L.E. (1987), «Managing technological development: Lessons from the newly industrializing countries». World Development, v. 15, no. 6, pp. 759-775.

DOSI, G. (1982), «Technological paradigms and technological trajectories: A suggested interpretation of the determinants and directions of technical change». Research Policy, v. 11, no. 3, pp. 147-162.

DOSI, G. (1988), «Sources, procedures and microeconomic effects of innovation». Journal of Economic Literature, v. 26, pp. 1120-1171.

FERRAZ, J.C.; KUPFER, D. e HAGUENAUER, L. (1997), Made in Brasil: Desafios Competitivos para a Indústria. Campus, Rio de Janeiro.

FIGUEIREDO P.N. (2004), «Aprendizagem tecnológica e inovação industrial em economias emergentes: Uma breve contribuição para o desenho e implementação de estudos empíricos e estratégias no Brasil.» Revista Brasileira de Inovação, v. 3, no. 2, jul/dez, pp. 323-361.

FRANSMAN, M. (1986), Technology and Economic Development. Wheatshead Books, Great Britain.

FURTADO, A. (Coord.). «Capacitação tecnológica, competitividade e política industrial: Uma abordagem setorial e por empresas líderes». IPEA, Brasília.

HASENCLEVER, L. e CASSIOLATO, J. (1998), "Capacitação tecnológica empresarial brasileira e transferência de tecnologia». Anais do Simpósio de Gestão da Inovação Tecnológica, 20, PGT/USP, São Paulo, pp. 309-321.

KIM, L. (2005), Da Imitação à Inovação: A Dinâmica do Aprendizado Tecnológico da Coréia. Editora da Unicamp, Campinas.

KIM, L. (2009), Gestão da Inovação: Conceitos, Métricas e Experiências de Empresas no Brasil. LTC, Rio de Janeiro.

LALL, S. (1992), «Technological capabilities and industrialization». World Development, vol. 20, no. 2, pp. 165-186.

LALL, S. (2000), «The technological structure and performance of developing country manufactured exports». Oxford Development Studies, v. 28, no. 3, pp. 337-369.

LALL, S. (2005), «A mudança tecnológica e a industrialização nas economias de industrialização recente da Ásia: Conquistas e desafios». In L. Kim e R.R. Nelson (Eds.), Tecnologia, Aprendizado e Inovação: As Experiências das Economias de Industrialização Recente. Editora da Unicamp, Campinas.

LEE, K.R. (1996), «The role of user firms in the innovation of machine tools: The Japanese case». Research Policy, 25, pp. 491-507.

LUNDVALL, B.A.; VANG, J.; JOSEPH, K.J. e CHAMINADE, C. (2009), «Innovation system research and developing countries». In A.B. Lundvall, K.J. Joseph, C. Chaminade e J. Vang, (Eds.), Handbook of Innovation Systems and Developing Countries. Building Domestic Capabilities in a Global Setting. Edward Elgar, Cheltenham, UK and Northampton, MA, USA.

LUNDVALL, B.A. (Ed.) (1992), National System of Innovation: Towards A Theory of Innovation and Interactive Learning. Printer, London.

LUNDVALL, B.A. (200), «Políticas de inovação na economia do aprendizado». Parcerias Estratégicas, n. ${ }^{\circ} 10$.

MALERBA, F. (2006), «Innovation and the evolution of industries». Journal of Evolutionary Economics, v. 16, no. 1-2, pp. 3-23.

MALERBA, F. (2002), «Sectoral systems of innovation and production». Research Policy, v. 31 , no. 2 , pp. $247-264$. 
65|Revista de GESTÃO dos Países de Língua Portuguesa

MALERBA, F. e ORSENIGO, L. (1993), «Technological regimes and behavior». Industrial and Corporate Change, v. 2, no. 1, pp. 45-71.

MALERBA, F. e ORSENIGO, L. (1996), «Schumpeterian patterns of innovation are technology-specific». Research Policy, v. 25, no. 3, pp. 451-478.

MARSILI, O. e VERSPAGEN, B. (2001), «Technological regimes and innovation: Looking for regularities in Dutch manufacturing». Druid Summer Conference 2001, Aalborg, Denmark.

NELSON, R. e WINTER, S. (1977), «In search of a useful theory of innovation». Research Policy, v. 5., pp. 36-78.

OREIRO, J.L.; PUNZO, L.; ARAÚJO, E. e SQUEFF, G. (2009), «Restrições macroeconômicas ao crescimento da economia brasileira: Diagnósticos e algumas proposições de política». Texto para discussão n. ${ }^{\circ}$ 1431, IPEA.

PENEDER, M. (2002), «Intangible investment and human resources». Journal of Evolutionary Economics, 12, pp. 107-134.

PICH, M.T.; LOCH, C.H. e DE MEYER, A. (2002), «On uncertainty, ambiguity, and complexity in project management». Management Science, v. 48, no. 8, pp. 1008-1023.

RADOSEVIC, S. (199), «International technology transfer policy: From 'contract bargaining' to 'sourcing', Technovation», vol. 19, no. 6/7, pp. 433-444.

ROMIJN, H. (1997), "Acquisition of technological capability in development: A quantitative case study of pakistan's capital goods sector». World Development, vol. 25, no. 3, pp. 359-311.

ROSENBERG, N. (1963), «Capital goods, technology and economic growth». Oxford Economic Papers, Oxford University Press.

SAHAL, D. (1984), «The innovation dynamics and technology cycles in the computer industry». Omega, 2, pp. 153-163.

STEWART, F. (1977), Technology and Underdevelopment. MacMillan Press, London.

TIDD, J.; BESSANT, J. e PAVITT, K. (2009), Managing Innovation: Integrating Technological, Market and Organizational Change. Wiley.

TSENG, M.M. e PILLER, F.T. (2003), The Customer Centric Enterprise: Advances in Mass Customization and Personalization. Springer.

VAN DIJK, M. (2000), «Technological regimes and industrial dynamics: The evidence from Dutch manufacturing». Industrial and Corporate Change, v. 9, no. 2, pp. 173-194.

VARUM, C.A.; MONTEIRO, L.V. e SAUR-AMARAL, I. (2009), «Dealing with the risks of innovation: A study of capital goods producers in Portugal». Global Business and Organizational Excellence, no. 28, pp. 34-51. 